\title{
Satisfaction Evaluation of Wudang Mountain's Smart Tourism Construction
}

\author{
Ran Su \\ School of Humanities and Social Science \\ Hubei University of Medicine, HBMU \\ Shiyan, Hubei Province, China
}

\author{
Bingke Zhu* \\ School of Public Health and Management \\ Hubei University of Medicine, HBMU \\ Shiyan, Hubei Province, China
}

\author{
Yang Zou \\ School of Computer \\ Central China Normal University, CCNU \\ Wuhan, Hubei, China
}

\begin{abstract}
With the development of information technology and smart city, smart tourism has become a compulsory option for tourists. This work firstly analyzed the construction of Wudang Mountain's smart tourism and constructed an evaluation index system of smart tourism satisfaction, including 5 first-level indicators as follows: smart service experience, consumption experience, environment and traffic, information release and feedback, infrastructure of smart scenic spots, and 18 second-level indicators. Then questionnaire analysis and IPA analysis were used to analyze overall tourists' satisfactory level of Wudang Mountain smart tourism construction and importanceperformance analysis. Finally, advice and suggestions were put forward from the aspects of guiding ideology, service system, portal website construction, travel early warning mechanism, information feedback, etc.
\end{abstract}

Keywords-Wudang Mountain; Smart Tourism; Evaluation; IPA

\section{INTRODUCTION}

Smart tourism is not only the product of the times; it is also the requirement of the development of the tourism [1]. Smart tourism refers to a new tourism development mode supported by artificial intelligence, cloud computing and mobile terminal communication technology [2]. It is based on terminal tourists' demand for tourism information services, and provides multilevel, multi-carrier and multi-form tourism information services through perceptive, integrational and interactive utilization of tourism information and resources. In recent years, the construction and development of China's smart tourism has been constantly advancing. In 2010, Zhenjiang, Jiangsu province took the lead in putting forward the concept and implementation of smart tourism in China. In 2012, the National Tourism Administration identified 18 "National Smart Tourism Pilot Cities"; the State Council designated 2014 as the year of smart tourism; in 2016, the State Council put forward the "Internet plus tourism" innovation and entrepreneurship action plan in the 13th Five-Year Tourism Development Plan, intending to construct a batch of national smart tourism cities,

Supported by Cultivating Project for Young Scholar at Hubei University of Medicine (Hubei University of Medicine) (Grant NO. 2016QDJRW03); Cultivating Project for Young Scholar at Hubei University of Medicine (Grant NO. 2016QDJRW06). smart tourism scenic spots, smart tourism enterprises and smart tourism villages.

The "Hubei Province Smart Tourism Construction Plan (2016-2020)" promulgated by the Hubei Provincial Department of Culture and Tourism proposes that through five years of tourism smart construction, it aims to form the tourism industry's intelligent pattern of self-driven and independent innovation, revitalize the tourism industry resources, break the barriers of information in the industry, and promote the integration and development of tourism industry chain. In response to the call, Wudang Mountain Scenic Area has aimed to build an "international high-end eco-cultural tourism destination" in recent years. It has built a strong "hardware" foundation through key projects, grasped the "software" platform construction optimization service, and accelerated the "touch network" upgrade of tourism, thus setting a new benchmark for smart tourism. By August 2017, Wudang Mountain has implemented 13 projects including the Intelligent Information Hall of Scenic Spots, Free WIFI Coverage in Core Attractions, and Urban Surveillance System of Scenic Spots. Currently, the construction of "face recognition ticketing system" and "inquiring tourism e-commerce platform" has provided assistance for the construction of smart tourism in Wudang Mountain. Smart construction, smart service and smart marketing have greatly improved the level of smart service in various scenic spots in Wudang Mountain. However, Wudang Mountain ranks 70th in the list of smart spots held by Internet Weekly in 2018. Compared with other famous mountains in China, such as Huangshan and Lushan, there is still huge gap in smart tourism construction. This paper aims to evaluate the satisfaction of the current situation of Wudang Mountain's Smart Tourism construction and put forward suggestions and strategies for improvement.

\section{LITERATURE REVIEW}

Gartner et al. (1993) [3] proposed Theory of Consistent Tourism Environment from the perspective of tourism environment (referring to tourism destinations, other intermediary channels such as tourism and transportation, and 
tourism and the theory of smart tourism, and conducted a

macro environment). Goossens et al. (2000) [4] believed that tourist satisfaction refers to the psychological state formed by the interaction between mentalities in the process of tourists purchasing tourism products. Kim et al. (2015) [5] focused on the satisfaction of smart tourism with attention on hotel satisfaction research, mainly through surveys to verify the impact of price and average quality on hotel satisfaction. Yoo et al. (2017)[6] studied the impact of the function of smart tourism technology (STT) on the satisfaction of tourism decision supportiveness.

In China, Wan Xucai et al. (2004) [7] defined tourist satisfaction as comprehensive evaluation of whether tourists meet the needs of their tourism activities in terms of tourism service facilities, service quality and landscape environment during the tour. Fu Quansheng (2005) [8] argued that tourist satisfaction refers to the degree of difference between the quality of tourist facilities, services, environment and landscape experienced by tourists and the expectations of tourists in the process of tourism activities in tourist destinations. Yao Guozhang et al. (2013) [9] concluded that the design of Intelligent Tourism evaluation index system can be divided into three levels, namely target level, system level, and state level. Cai Rongrong et al. (2015) [10] constructed a smart tourism satisfaction model ITSI based on the six elements of questionnaire survey in Nanjing for empirical research. Liu Chao et al. Wang Xia (2015) [11] studied the evaluation index system of the smart scenic spot from the perspective of tourists, and used Factor Analysis Method and the Fuzzy Comprehensive Evaluation Method to conduct an empirical evaluation of the Nanjing Confucius Temple. Xu Chunhong (2016) [12] took Ningbo City as an example to obtain the evaluation model of urban tourism public information service system and the evaluation value of tourists by IPA method. Deng Zhaochuan (2018) [13] analyzed from four application systems contained in smart tourism including service, business, management and wisdom, and proposed the basic framework of the smart tourism evaluation system.

\section{CONSTRUCTION AND APPLICATION OF EVALUATION MODEL}

\section{A. Evaluation Index System}

Following the principles of being scientific, objective and maneuverable, this paper constructs an evaluation index system of tourist satisfaction in Wudang Mountain, which consists of 5 first level indicators and 18 two level indicators, as shown in Table I.

TABLE I. EVALUATION INDEX SySTEM OF SATISFACTION DEgREE OF SMART TOURISM CONSTRUCTION IN WUDANG

\begin{tabular}{|c|c|c|c|}
\hline Level 1 Indicator & Level 2 Indicator & Level 1 Indicator & Level 2 Indicator \\
\hline \multirow{3}{*}{$\begin{array}{l}\text { Intelligent Service } \\
\text { Experience(A) }\end{array}$} & Tourist Route Recommendation(A1) & \multirow{4}{*}{$\begin{array}{l}\text { Information Release and } \\
\text { Feedback(D) }\end{array}$} & Tourism Culture Propaganda(D1) \\
\hline & Digital Interpretation of Cultural Relics(A2) & & $\begin{array}{l}\text { Real-time Information Broadcasting in } \\
\text { Scenic Spots(D2) }\end{array}$ \\
\hline & Smart Service Facility Completeness(A3) & & $\begin{array}{l}\text { Teaching of Information Equipment } \\
\text { Usage(D3) }\end{array}$ \\
\hline \multirow{3}{*}{ Consumption Experience(B) } & Convenience of Online Ticket Purchase(B1) & & Complaint Management(D4) \\
\hline & $\begin{array}{l}\text { Online Cultural Products } \\
\text { Recommendation(B2) }\end{array}$ & \multirow{5}{*}{$\begin{array}{l}\text { Smart Scenic Area } \\
\text { Infrastructure(E) }\end{array}$} & Wireless Network Coverage(E1) \\
\hline & $\begin{array}{c}\text { Convenience of Online Accommodation } \\
\text { Booking(B3) }\end{array}$ & & Electronic Tour Guide(E2) \\
\hline \multirow{3}{*}{$\begin{array}{l}\text { Environment and } \\
\text { Transportation(C) }\end{array}$} & $\begin{array}{l}\text { Vehicle Scheduling and Parking } \\
\text { Management(C1) }\end{array}$ & & Video Surveillance Coverage(E3) \\
\hline & $\begin{array}{l}\text { Statistics of Tourist Number and Tourist } \\
\text { Guidance(C2) }\end{array}$ & & Overall Construction of Portal Websites(E4) \\
\hline & Natural Environmental Monitoring(C3) & & Mobile Tourism Information Service(E5) \\
\hline
\end{tabular}

\section{B. Questionnaire Design}

According to the Wudang Mountain's Smart Tourism Construction Satisfaction Evaluation Index System we designed the questionnaire. The questionnaire was divided into two parts: the first part was the demographic characteristics, including gender, age, education, occupation, income, and source of tourists. The second part was the satisfaction after actual experience including 18 main indicators. By using Likert Scale, the grades were divided into five scales: "very unsatisfied, unsatisfied, normal, satisfied, very satisfied”, and assigned score “1, 2, 3, 4, 5” respectively.

After the questionnaire design was completed, the pre-test is carried out. The reliability and validity of the questionnaire were analyzed by SPSS. The results show that the reliability coefficient $\alpha$ was 0.922 , greater than 0.8 , indicating that the results were consistent; the KMO value was 0.839 , greater than 0.6 , and the approximate chi-square test value calculated by Barrett spherical test was 3175.667, and the $P$ value was 0.000 (less than 0.001). The Barrett spherical test was rejected, indicating that the sampling instrument of the questionnaire was highly consistent. Finally, 120 questionnaires were collected by means of field questionnaires and online questionnaires, of which 116 were valid questionnaires and reaching validity of $96.67 \%$.

\section{Analysis of survey results}

1) Demographic analysis

According to the analysis of questionnaire, the proportion of males surveyed is $50.9 \%$, and the proportion of females is $49.1 \%$. The proportion is relatively balanced. The age distribution of respondents is as follows: under 24 (38.1\%), 2544 (28.1\%), 45-64(22.8\%), over 65(11\%). The education level is mainly concentrated in bachelor degree and above (35.52\%), and Junior college(20.34\%), high school and below(19.83), master and above(24.31\%). The majority respondents are from Hubei province, with the percentage of $60.34 \%$. This indicates that Wudang Mountain tourists tend to be younger and local. 
However, it is also necessary to consider the limitations of the questionnaire population and the limitations of the sample size; the occupations of the respondents are mainly students (30.03\%) and enterprise employees (20.21\%), self-employed(17.76\%), official staff(8.72\%), and others(23.28\%); the income level is mainly concentrated in 3001-5000 (30.52\%), $1001-3000$ (23.79\%), and below 3000 accounts $31.38 \%$, and over 8000 is $7.78 \%$. Most tourists' income is at the middle level.

\section{2) Descriptive statistical analysis}

In this paper, the "Wudang Mountain Smart Tourism Construction Satisfaction" is taken as the dependent variable Y, and the value range is $1-5$, which is expressed as "very unsatisfied, unsatisfied, general, satisfactory, very satisfied”, with 18 evaluation indicators as independent variables, descriptive statistical analysis was performed as Table II.

TABLE II. ANALYSIS OF DESCRIPTIVE STATISTIC OF QUESTIONNAIRE ON SATISFACTION OF SMART TOURISM CONSTRUCTION IN WUdANG MOUNTAIN

\begin{tabular}{|c|c|c|c|c|c|c|}
\hline Variable & Sample Size & Min value & Max Value & Average Value & Standard Deviation & Median \\
\hline A1 & 116 & 1 & 5 & 3.37 & 0.94 & 3 \\
\hline A2 & 116 & 1 & 5 & 3.27 & 0.84 & 3 \\
\hline A3 & 116 & 1 & 5 & 3.28 & 0.93 & 3 \\
\hline B1 & 116 & 1 & 5 & 3.41 & 0.87 & 3 \\
\hline B2 & 116 & 1 & 5 & 3.05 & 0.85 & 3 \\
\hline B3 & 116 & 1 & 5 & 3.16 & 0.88 & 3 \\
\hline C1 & 116 & 1 & 5 & 3.4 & 0.97 & 3 \\
\hline C2 & 116 & 1 & 5 & 3.22 & 0.85 & 3 \\
\hline C3 & 116 & 1 & 5 & 3.42 & 0.81 & 3 \\
\hline D1 & 116 & 1 & 5 & 3.42 & 0.81 & 3 \\
\hline D2 & 116 & 1 & 5 & 3.45 & 0.86 & 3 \\
\hline D3 & 116 & 1 & 5 & 3.35 & 0.86 & 3 \\
\hline D4 & 116 & 1 & 5 & 3.2 & 0.85 & 3 \\
\hline E1 & 116 & 1 & 5 & 3.36 & 1 & 3 \\
\hline E2 & 116 & 1 & 5 & 3.29 & 0.86 & 3 \\
\hline E3 & 116 & 1 & 5 & 3.38 & 0.86 & 3 \\
\hline E4 & 116 & 1 & 5 & 3.21 & 0.8 & 3 \\
\hline E5 & 116 & 1 & 5 & 3.41 & 0.86 & 3 \\
\hline
\end{tabular}

It can be seen from Table III that the average value of each evaluation variable is between 3-4 points and is at a medium level. To some extent, the satisfaction of tourists in Wudang Mountain smart tourism construction is between "general" and "satisfactory". Among them, the convenience of online ticket purchase, vehicle dispatch management, tourism culture publicity, scenic real-time information broadcast, mobile travel information service and other services are relatively highly marked, this benefits from the emphasis on the construction of smart tourism in Wudang Mountain in recent years. Since 2018, the Public Security Bureau in Wudang Mountain Special Administrative Region has invested 32 million yuan to build a video "Skynet" project, and established a flat command system of "up-down linkage, horizontal response, and efficient operation" to strengthen data integration and joint implementation, besides, it has also realized the predicting, directing, locating as well as tracking of the tourists, vehicles and other objects. The command center can monitor the scene in real time through the "Sky Eye" monitoring system according to the congestion index and emergency situation of the tourists, and guide the on-site police to deal with it quickly and effectively. In September 2018, the new ticket sales inspection system of Wudang Mountain came into operation. Visitors can purchase tickets directly by mobile phone or in the smart ticket vending machine system. You can enter the park with ID card, QR code, or by scanning your face, etc. This is of great convenience for tourists. However, services such as digital interpretation of cultural relics, the recommendation of featured cultural goods, electronic tour guides, complaint management, and overall construction of portals have relatively low scores.

\section{3) IPA Analysis}

IPA analysis method, i.e. importance-performance analysis method, takes importance (weight) as horizontal axis, performance (satisfaction) as vertical axis, draws twodimensional plan, and divides the two-dimensional plane into four areas: advantage area (Area A), maintenance area (Area B), to be improved area (Area C) and particularly noteworthy area (Area D) according to the mean of horizontal and vertical coordinates (importance mean, satisfaction mean). Calculate the mean of importance and the mean of satisfaction before plotting the IPA analysis chart, as shown in Table IV, and then make an IPA analysis, as shown in Fig. 1.

TABLE III. ANALYSES ON THE IMPORTANCE OF THE ELEMENTS OF SMART TOURISM SATISFACTION IN WUDANG MOUNTAIN

\begin{tabular}{|c|c|c|c|c|c|}
\hline Indicator & Mean of Importance & Rank & Mean of Satisfaction & Rank & Mean Gap \\
\hline Tourism Route Recommendation & 2.95 & 16 & 3.37 & 8 & 0.42 \\
\hline Digital Interpretation of Cultural Relics & 2.8 & 17 & 3.27 & 13 & 0.47 \\
\hline Intelligent Service Facility Completeness & 3.13 & 8 & 3.28 & 12 & 0.15 \\
\hline Convenience of Online Ticket Purchase & 3.34 & 2 & 3.41 & 4 & 0.07 \\
\hline Online Recommendation of Cultural Commodities & 2.7 & 18 & 3.05 & 18 & 0.35 \\
\hline Convenience of Online Accommodation Booking & 3.18 & 6 & 3.16 & 17 & -0.02 \\
\hline Vehicle Scheduling and Parking Management & 3.09 & 9 & 3.4 & 6 & 0.31 \\
\hline Statistics of Tourist Number and Tourist Guidance & 2.98 & 14 & 3.22 & 14 & 0.24 \\
\hline Monitoring of Natural Environment & 3.16 & 7 & 3.42 & 2 & 0.26 \\
\hline
\end{tabular}




\begin{tabular}{|c|c|c|c|c|c|}
\hline \multicolumn{6}{|c|}{ Cont.to TABLE III } \\
\hline Tourism Culture Propaganda & 3.07 & 10 & 3.42 & 3 & 0.35 \\
\hline $\begin{array}{l}\text { Real-time Information Broadcasting in Scenic } \\
\text { Spots }\end{array}$ & 3.42 & 1 & 3.45 & 1 & 0.03 \\
\hline Informatization Equipment in Teaching & 2.95 & 15 & 3.35 & 10 & 0.4 \\
\hline Compliant Management & 3.22 & 4 & 3.2 & 16 & -0.02 \\
\hline Wireless Network Coverage & 3.22 & 5 & 3.36 & 9 & 0.14 \\
\hline Electronic Guidance & 3.06 & 11 & 3.29 & 11 & 0.23 \\
\hline Video Surveillance Coverage & 3.25 & 3 & 3.38 & 7 & 0.13 \\
\hline Portal Website Construction & 3 & 13 & 3.21 & 15 & 0.21 \\
\hline Mobile Service of Tourism Information & 3.06 & 12 & 3.41 & 5 & 0.35 \\
\hline Overall Mean & 3.09 & & 3.31 & & \\
\hline
\end{tabular}

Generally speaking, the average satisfaction of tourists for Wudang Mountain smart tourism construction is 3.31, which is between "general” and "satisfactory".

To be specific:

(a) The first quadrant, advantage area, is the area where the importance and satisfaction are higher than average. There are six variables in this area: the convenience of online ticket purchasing, vehicle dispatching and parking management, natural environment monitoring, real-time information broadcasting, wireless network coverage and video surveillance coverage. It proves that tourists pay more attention to these aspects and are satisfied with the current construction level of Wudang Mountain; this can be used as an advantage factor to attract tourists.

(b) The second quadrant, maintenance area, area where the importance line is relatively low and the satisfaction is relatively high. The area has tourist route recommendation, tourism culture propaganda, information technology equipment usage teaching, and mobile tourism information service, indicating that tourists pay more attention to the promotion of basic tourism information, and prefer personalized travel customization or deeper travel experience.

(c) The third quadrant, to be improved area, is the region where the importance and satisfaction are relatively low. The region has digital interpretation of cultural relics, online cultural product recommendation, tourist statistics and tourist guidance, electronic tour guides, and overall construction of the portal. Visitors hold that these factors are relatively less important and are less satisfied with these factors.

(d) The fourth quadrant, particularly noteworthy area, is an area of higher importance but lower satisfaction. The region has service variables such as the completeness of intelligent service facilities, the convenience of online accommodation booking, and complaint management. Visitors pay more attention to these services, but their satisfaction is relatively low. Visitors now pay more attention to the experience of service equipment and their own demands; therefore, construction in this area needs to be improved.

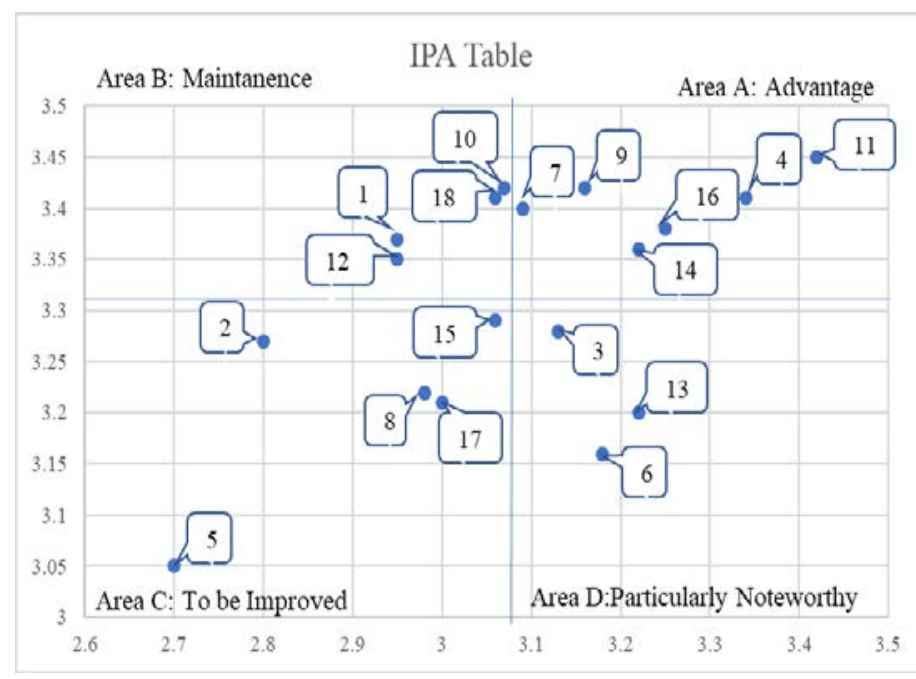

Fig.1. IPA Analysis of Satisfaction Degree of Smart Tourism Construction in Wudang Mountain

\section{SUGGESTIONS}

\section{A. Adhering to the Strategic Thought and Principle of National Tourism Informatization}

In the process of informationization construction, Wudang Mountain should adhere to the policy of "overall planning, market-oriented, application-oriented, resource sharing, safety and reliability" of national informationization construction, take deepening information application as the main line of informationization construction, and comprehensively enhance the depth of tourism informationization in Wudang Mountain; Utilizing the latest information technology, taking the coexistence of efficiency and quality, the equal emphasis on management and construction as the basic principle, we can improve the level of tourism informatization in Wudang Mountain; Formulate and improve tourism informatization policies and norms, and provide a good policy environment for the construction of informatization; Intensify the construction of Wudang Mountain's cultural brand and expand the scope of publicity so as to promote the construction of Wudang Mountain's tourism informatization in an all-round way.

\section{B. Optimizing tourism services and improve service system}

In order to improve the overall service quality of Wudang Mountain Scenic Area, Wudang Mountain Scenic Area should formulate guidelines for tourism-related practitioners, provide 
In terms of mobile applications, Wudang Mountain launched the "Handheld Wudang" client and "Wudang Mountain Smart Guide App", but in the process of downloading, this is not avaliabe in IOS system, and the update of the "Handheld Wudang" WeChat widget program is delayed, the travel reservation can only see several hotel reservation links, "Cultural products" and "Characteristic homestay" are empty links. In the construction of mobile applications, Wudang Mountain Scenic Spot needs to meet the personalized needs of tourists and provide more convenient services for tourists on the basis of complete basic functions.

\section{E. Establishing tourism early warning mechanism}

Travel safety is one of the most concerned problems for tourists. The construction of the scenic spot should include the following aspects as well: establishing a tourism early warning mechanism, make correct prediction and analysis of the flow of tourists and take appropriate measures to guide and control it, strengthen the collection, processing and release of tourism quality information, and promote scientific management to ensure tourism safety.

\section{F. Improving the tourist information feedback channel}

The purpose of smart tourism is to provide tourists with a better travel experience, so meet the demands of tourists and listen to the feedback of tourists is an important part of smart tourism construction. Therefore, as for complaints from tourists, except complaints through phone channels, online access should also be available. For instance, "Complaints \& Suggestion" column should be set on the portal website, or visitors can provide comments, suggestions or complaints through Weibo, WeChat public accounts etc. Wudang Mountain scenic spot should set up a dedicated person to respond in a timely manner, solve the feedback of tourists, and establish a perfect complaints and evaluation feedback system.

\section{CONCLUSION}

This paper evaluated and analyzed the satisfaction of Wudang Mountain's Smart Tourism construction. Some significant results are shown with statistical analysis and IPA analysis.

- Through deliberation on current status of the construction of Wudang Mountain's smart tourism, the satisfaction index system consisted of 5 first-level system and 18 second-level indicators.

- According to questionnaire analysis, the satisfaction of tourists in Wudang Mountain smart tourism construction is between "general" and "satisfactory".

- Based on APA analysis, we concluded that visitors paid more attention to the completeness of intelligent service facilities, the convenience of online accommodation booking, and complaint management, but the satisfaction was relatively low, therefore, construction in this area needs to be improved. well-known tourism APP platforms, such as Mafengwo and Tuniu, to formulate scientific marketing themes, innovate marketing concepts, highlight the unique tourism culture of Wudang Mountain, attract tourists to participate actively in it, and form new ways of communication and marketing. 
[6] Yoo C W, Goo J, Huang C D, et al. Improving travel decision support satisfaction with smart tourism technologies: a framework of tourist elaboration likelihood and self-efficacy. Technological Forecasting \& Social Change, 2016, pp.330-341.

My heart felt gratitude goes to my colleagues who have always been offering me valuable advice and guidance during the whole research, without their instructions and criticism, this thesis would not be completed.

\section{REFERENCES}

[1] Wang Wenjian. Retrospect and prospect of domestic smart tourism research-Statistical analysis based on CNKI related literature. Journal of Heilongjiang Ecological Engineering Vocational College, 2017, pp. 21-24. (In Chinese)

[2] Liu Banfan, He Taisu, ZhangBei, Li Yanjing. Research on collaborative development of Beijing-Tianjin-Hebei leisure industry (II)-taking Beijing-Tianjin-Hebei smart tourism innovation model and platform construction as an example. China Collective Economy, 2016, pp.5-6. (In Chinese)

[3] Gartner, W.C. Image Formation process. Journal of Travel and Tourism Marketing, 1993, pp.197-212.

[4] Goossens, Research, C. Tourism information and pleasure motivation. Annals of Tourism, 2000, pp.301-321.

[5] Kim J Y, Canina L. An analysis of smart tourism system satisfaction scores. Computers in Human Behavior, 2015, pp.610-617.

[7] Wan Xucai, Ding Min, Song Ping. Domestic tourist satisfaction sssessment and regional differences in Nanjing. China Economist, 2004, pp.246-247. (In Chinese)

[8] Fu Quansheng. Review on the research on tourist satisfaction theory. Geography and Geo-Information Science, 2005, pp.90-94. (In Chinese)

[9] Yao Guozhang, ChenFei, Zhou Xiaoping. Research on the evaluation system of intelligent tourism. Tourism Economy, 2013, pp.110-111. (In Chinese)

[10] Cai Rongrong, ZhangWeiya. Empirical study on satisfaction degree of intelligent tourism based on structural equation. Resource Development and Market, 2015, pp.378-384. (In Chinese)

[11] Wang Xia, Zhen Feng. The evaluation system and empirical analysis of intelligent scenic spot based on the perspective of tourists. Progress in Geography, 2015, pp.448-456. (In Chinese)

[12] Xu Chunhong Evaluation of urban tourism public information service system under the background of smart city construction: taking Ningbo City as an example. Tourism Research, 2016, pp.40-47. (In Chinese)

[13] Deng Chaochuan. Research on the evaluation system of smart tourism. Tourism Overview, 2018, pp.18. (In Chinese) 